\title{
LA CONTRADANZA EN ESPAÑA EN EL SIGLO XVIII: FERRIOL Y BOXERAUS, MINGUET E YROL Y LOS BAILES PÚBLICOS'.
}

\author{
Clara Rico Osés \\ Université de Nice Sophia-Antipolis
}

\section{Resumen}

La contradanza llegó a España, a través de Francia, durante la primera mitad del siglo XVIII y fue codificada por los autores de tratados de danza francesa en español (Ferriol y Minguet). Ambos describen dos tipos básicos de contradanza: la inglesa y la francesa y coreografían varios ejemplos siguiendo los modelos de tratadistas franceses como Feuillet (1706) o De la Cuisse (172). Durante la segunda mitad de siglo, las contradanzas se convierten en la esencia de los bailes públicos; prueba de ello son los numerosos recopilatorios de contradanzas, inglesas y francesas, que se interpretaban en dichos bailes.

Este estudio se propone e xplorar la e volución de la contradanza en España en el siglo XVIII: ¿Es posible establecer unas características propias?, ¿Fueron los compositores y coreógrafos españoles capaces de escribir sus propias coreografías?, ¿Hast a qué punto fueron asimilados los sistemas franceses de notación?

\section{Palabras clave:}

Danza, baile, coreografía, contradanza, country-dance, contredanse, siglo XVIII, Antiguo Régimen, España, Francia.

\begin{abstract}
The country-dance arrived to Spain through the France border during the first half of the $18^{\text {th }}$ century and it was codified in Spanish language by the French dance treatises authors (Ferriol and Minguet). Both described two basic categories of countrydance: the English and the French, and they choreographed several examples following the pattern of treatises created by authors such as Feuillet (1706) and De la Cuisse (1762). During the second half of the century country-dance became essential in public balls, proof of which are the numerous English and French country-dance compilations in performed within those balls.

The present study aims to explore the evolution of country-dance in Spain during the $18^{\text {th }}$ century: Is it possible to establish certain particular characteristics? Were Spanish choreographers and composers able to write their o wn choreographies? To what extent were the French notation systems assimilated by Spanish authors?
\end{abstract}

\section{Keywords:}

Dance, ball, choreography, country-dance, contredanse, contradanza, $18^{\text {th }}$ century, Old Regime, Spain, France.

1 La autora ha sido financiada con una Ayuda para la contratación de jóvenes doctores extranjeros en universidades y centros de investigación españoles, MEC-07-sB2006-0055 y con un contrato postdoctoral del Ministerio de Ciencia e Inno vación (Programa Nacional de Movilidad de Recursos Humanos del Plan Nacional I+D+I 2008-2011. -2008-0711). 
La contradanza llega a España de la mano de los tratados de danza franceses que se difundieron por todas las cortes de Europa durante la primera mitad del sigloxvIII. Los tratadistas españoles se inspiraron en ellos, adaptando y reinterpretando ese noble arte francés' los primeros intentos de codificación de la contradanza en España, a nivel más teórico que práctico, se deben a Bartholomé Ferriol y Box eraus ${ }^{3}$ y a Pablo Minguet e Yrol ${ }^{4}$. A medida que dicho baile se va poniendo de moda, entra a formar parte de los bailes públicos y ya en la se gunda mitad de siglo encontramos varias colecciones de tipo práctico, con música y explicaciones en prosa sobre el correcto modo de bailar la contradanza.

\section{LOS TRATADOS ESPAÑOLES Y SUS AUTORES}

No está claro cuál de los dos autores españoles publicó antes su obra; ambos declaran ser los primeros en escribir sobre este tema en castellano. A juzgar por sus palabras, todo indica que lo fue Pablo Minguet e Yrol, aunque no se ha conserv ado ni un solo ejemplar de esa primera edición que él anuncia en 1758:

“el año 1733 hice la primera impresión, después he sacado diferentes y cada vez le he añadido algunas danzas y contradanzas curiosas; he sido el primer autor en España de este arte"

Una noticia de la Gaceta de Madrid con fecha de 16 de julio de 1737 anuncia la publicación de un "librito nuevo: Arte de danzar a la francesa adornado con láminas...", anuncio que se repite en años posteriores $(1738,1740,1745 \text { y } 1749)^{6}$.

Sin embargo, las ediciones de El arte de danzar a la francesa de Minguet e Yrol que se pueden consultar hoy en la Biblioteca Nacional de España datan de los años 50 del sigloxviII y son posteriores a la obra de Bartholomé Ferriol y Boxeraus, las Reglas útiles para los aficionados al danzar de 1745, de las que también se conservan varios ejemplares en la Biblioteca Nacional de España.

La obra de Minguet evoluciona a lo largo de los años. Veremos que entre los años 30 y los años

2 Sobre la recepción de la danza francesa en la España del siglo XVIII ver: Raventós I FreiXA, Jordi: "La danza francesa en Barcelona durante el siglo xVIII: recepción y transformación", en Revista Transcultural de Música. Transcultural Music Review, $\mathrm{n}^{\circ}$ 2, noviembre 1996. (Revista electrónica: www2.uji.es/trans). CARreIRA, Xoan M.: "La recepción del ballet d'action en la Península Ibérica, 1789-1800”, en Actas del vi Encuentro de Música Ibérica, Revista Portuguesa de Musicología, n 1, (1991), pp. 211-226. Russell, Craig H.: "Imported influences in 17th and 18 th century guitar music in Spain", en Actas del Congreso Internacional España en la música de occidente. Madrid, Instituto Nacional de las Artes Escénicas y de la Música, 1987, v ol. 1, p. 385-403. Mera, Guadalupe: "La danza, el baile, los saraos, la danza escénica y los bailes populares, notas y precisiones sobre su estado en la España ilustrada", en Teatro y música en España: los géneros breves en la $2^{a}$ mitad del siglo XVIII. Madrid, UAM, 2008, pp. 460-479. 1745 .

3 Ferriol y Boxeraus, Bartholomé: Reglas útiles para los aficionados al danza r... Capua, a costa de Joseph Testore,

4 Minguet e Yrol, Pablo: Arte de danzar a la francesa. Madrid, en la oficina del autor, [s.u.] 1758.

5 Minguet e Yrol, Pablo: Quadernillo curioso de veinte contradanzas nuevas. Madrid, 1758, p. 16.

6 Sustaeta Llombart, Ignacio: La música en las fuentes hemerográficas del siglo XVIII español, referencias musicales en la Gaceta de Madrid y artículos de música en los papeles periódicos madrileños , Emilio Casares dir., Madrid, Universidad Complutense de Madrid, Facultad de Ciencias de la Información, Dto: Filología III, 1993, tomo III, p. 160. 
60 publica una serie de tratados breves que varían, se amplían o se mejoran, en función de las últimas novedades en temas de danza. Se gún esto, Ferriol en 1745 debería conocer las primeras obras de Minguet y Minguet, en sus últimas publicaciones, debería conocer la obra de Ferriol. Por el contrario, ninguno de los dos hace alusión al otro.

Ferriol deja entrever en su prólogo que no conocía aquellas primeras ediciones de Minguet:

"ninguno se ha encontrado que se escri viese en castellano las re glas de todos los diferentes pasos de la danza francesa, con el brazeo correspondiente en cada uno; ni la e xplicación demonstrativa de la chorographia, algunos bayles de corte, distintas contradanzas...".

Y Minguet, en los años 60, insiste en esa e xclusiva de la publicación de libros de danza en castellano. Además, en calidad de buen vendedor, no pierde oportunidad de hacer propaganda:

"He sido el único en España de dichos bailes en chore graphia desde el año 1733 y los v endo juntos y separados"7.

Dado que, de los dos autores citados, el tratado conservado de fecha más temprana es de Ferriol y teniendo en cuenta que la obra de Minguet es más compleja y se prolonga más en el tiempo, comenzaremos el análisis de las contradanzas por Ferriol ${ }^{8}$.

Sobre la vida de Ferriol y Box eraus no se sabe mucho. Él no se presenta como maestro de baile ni como bailarín, pero en su tratado podemos encontrar algunas pistas sobre su vida y su formación. Maurice Esses ${ }^{9}$ sugiere que tal $\mathrm{v}$ ez fuera hijo de madre catalana y de padre francés y recopila esas pocas pistas: Ferriol cita a un tal Monsieur Ferriol que fue embajador de Francia en Constantinopla y habla de "un curso de quatro maestros, que tuve en el espacio de siete años"10.

También presenta en su prólogo la "metodología” que ha utilizado para la realización de su obra:

"no he fundado esta máquina en los cimientos de mi idea; sino arre glándome a los documentos de los más célebres authores y en la práctica de diferentes maestros"11.

Además dice haber obtenido

"respuestas que me han dado más perfectos operarios de distintas naciones a los que he preguntado".

7 Minguet e Yrol, P.: El noble arte de danzar a la francesa y a la española. Con licencia: en Madrid, se hallará éste y las demás obras suyas útiles y de diferentes artes, para toda clase de personas en su casa, p. 5.

8 La edición del tratado de Ferriol que se и a utilizar es la que se encuentra en la Sala Barbieri de la Biblioteca Nacionade Madrid. Ferriol y BoXeraus, Bartolomé: Reglas útiles para los aficionados a danzar... E-Mn M/860. Debido a su mala paginación y para no llevar a mal entendidos, cada vez que se cite, se dará el $\mathrm{n}^{\circ}$ del tratado, el nombre del capítulo y el $\mathrm{n}^{\circ}$ de la página.

9 Esses, Maurice: Dance and instrumental diferencias in Spain during the $17^{\text {th }}$ and early $18^{\text {th }}$ centuries. Nue va York, Pendragon Press, 1992, vol. 1, p. 439.

10 Ferriol y BoXeraus, Bartolomé: op. cit., Introducción, p. 3.

11 Ferriol y Boxeraus, Bartolomé: op. cit., Prólogo. 
De esta forma, deja bien claro desde el principio que su trabajo no es un estudio personal sino que se está basando en otros autores. Sobre este aspecto volverá más adelante: en el capítulo 3 del tratado III anuncia que va a seguir los modelos de Pierre Rameau:

"la mejor y más fácil idea, que se ha discurrido en esta Arte, es la Chorographia (...). Ay de dos especies, que es Antigua y Moderna, la Antigua es inventada por Mons. Feuillet; y la Moderna por Mons. Rameau y por ser esta última más fácil y más clara, las e xplicaré para e vitar alguna confusión a los Principiantes"12.

Raoul Auger Feuillet publica su Chorégraphie ou l'art de décrire la danse en 1700 y veinticinco años más tarde aparecen las obras de Pierre Rameau, Le maître à danser y el Abbrégé de la nouvelle méthode dans l'art d'écrire et de tracer toutes sortes de danses de ville . Rameau se basaba en los dictados de Feuillet pero mejoraba el sistema de coreografía y aportaba además una guía práctica sobre el arte de la danza a través de explicaciones en prosa ${ }^{13}$.

En el título de su Abbrégé, Pierre Rameau se presenta como "Maître à Danser Ordinaire de la Maison de Sa Majesté Catholique, la Reine Seconde Douairière d'Espagne". Dicha afirmación ha sembrado dudas sobre su posible trabajo en España, sin embar go, no parece que hubiera lle gado a residir allí. Esa segunda viuda hace referencia a Luisa Isabel de Orleáns, viuda de Luis I de España, el hijo primogénito de Felipe v que sucedió a su padre cuando éste abdicó en 1722, pero que murió a los pocos meses de ser coronado.Al fallecer el rey, Luisa Isabel regresó a Paris, donde seguramente habría contratado los servicios de Pierre Rameau como maestro de danza ${ }^{14}$. La primera viuda era Mariana de Neoburgo, la segunda esposa de Carlos II, el último Austria.

Efectivamente, Ferriol trata en sus Reglas útiles los mismos temas que Rameau en su Maître à danser. Sin embargo la estructura es algo diferente. Mientras que Rameau divide su libro en dos partes, Ferriol realiza tres tratados. Comienza el primero ("donde se contienen todos los diferentes pasos de la danza francesa") con temas generales que suelen abrir los escritos de esta época: el origen de la danza, la utilidad del saber danzar, la theorica en este arte... Y acaba con temas más específicos de la danza francesa: las ceremonias de los bailes, el gobierno del cuerpo en este tipo de danza y, por fin, la explicación de las posiciones y el modo de formar todos los diferentes pasos de la danza francesa. Estos últimos se corresponden con capítulos de la primera parte del tratado de Rameau.

El segundo tratado es prácticamente igual que la se gunda parte de Le Maître à danser y en él "se contiene el braceo correspondiente en cada paso". El tercer tratado se refiere a "la demonstración

12 Ferriol y Boxeraus, Bartolomé: op. cit., Tratado iII, Capítulo 3, p. 213. El mismo Pierre Rameau habla de esa diferencia entre la antigua notación de Feuillet y la moderna y publica una tabla comparati va de los pasos en ambos sistemas. Ver RAMEAU, Pierre: Abbrégé de la nouvelle méthode dans l'art d'écrire ou de tracer toutes sortes des danses de villeParis, chez l'auteur, 1725, pp. 86-93.

13 Sobre los sistemas de notación en la Francia del sigloviI ver: Pierce, Ken: "Dance notation systems in late 17th century France", en Early Music, (May, 1998), pp. 287-299.

14 Astier, Régine: "Pierre Rameau", enInternational Enciclopedia of Dance. Selma Jeanne Cohen, éd. New York, Oxford, Oxford University Press, 1998. 
y declaración de algunas danzas de corte, chorographia y distintas contradanzas". Comienza con la explicación del minué, que ya había sido descrito por Rameau en la primera parte de su tratado y del que toma prestadas varias láminas. Sin embargo, Ferriol continúa con las instrucciones para danzar el passapie y la contradanza, de las que Rameau no se había ocupado en ninguno de sus tratados.

En cuanto a Pablo Minguet eYrol, tampoco se tienen demasiados datos sobre su vida. Se autodefine como un "grabador de sellos, láminas, firmas y otras cosas" y fue discípulo de Juan Bernabé łomino ${ }^{15}$, considerado éste como el promotor del resugimiento del grabado en España ${ }^{6}$. Además de grabador fue teórico, escritor y editor y desarrolló aspectos muy dispares; publicó obras de temas lúdicos ( Juegos de manos ó sea Arte de hacer diabluras y juegos de prendas... ）, religiosos ( Meditaciones para el Santo Sacrificio de la Misa...), musicales (tratados de música instrumental comoReglas y advertencias generales que enseñan el modo de tañer todos los instrumentos...) y de danza ${ }^{17}$.

Como teórico de la danza, Minguet publica cinco tratados, no tan lagos como el de Ferriol, que se han conservado en la Biblioteca Nacional de España en encuadernaciones conjuntas. Cada una de las seis encuadernaciones que ha llegado a nuestros días presenta por lo menos tres de los cinco tratados: Arte de danzar a la francesa. Breve tratado de los pasos de danzar a la española. Cuadernillo curioso de veinte contradanzas nuevas. Breve explicación de diferentes danzas y contradanzas. El noble arte de danzar a la francesa ${ }^{18}$. Al parecer él las vendía juntas o por separado: "Las danzas fáciles se venden en un cuaderno, las otras en otro, las contradanzas en otro y todas juntas en un libro encuadernado"19.

El primer tratado sigue fielmente los mismos aspectos que Rameau y que Ferriol, pero descritos de manera más superficial; explica las posiciones, las re verencias, el minuete y el passapie, pero no se detiene a analizar la correcta manera de ejecutar cada paso o a presentar con detenimiento el tipo de braceo que acompaña a los movimientos de las piernas. En el segundo se detallan los pasos que se pueden utilizar para los bailes a la española; en este tratado se ha visto una continuidad con los bailes del siglo XVII español, relacionando a Minguet con Esquivel ${ }^{20}$.

Como se desprende de los títulos ya citados, Minguet dedica el tercer y el cuarto tratados a las explicaciones de las contradanzas, bailes que serán analizados también en el último de sus tratados. En este sentido, actúa como Ferriol y se aleja de los dictados de Rameau que, como ya se ha dicho, no incluye este tipo de danza en su obra.

15 Rodriguez de la Flor, Fernando: "Vaubán Lúdico (Un grabado de Pablo Minguet e Yrol, "Juegos de la fortificación”, Madrid, 1752)", en Boletín del Museo e Instituto Camón Aznar, XXIV (1986), p. 116.

16 Esteve Botey, Francisco: Historia del grabado. Barcelona, Clan, Técnicas artísticas, Editorial Labor ,1993, p. 303.

17 Gallardo, Bartolomé José: Ensayo de una Biblioteca española de libros raros y curiosos . 3, Madrid, Gredos, 1888. Palau y Dulcet, Antonio: Manual del librero hispanoamericano, bibliografía general española e hispanoamericana desde la invención de la imprenta hasta nuestros tiempos... Barcelona, Librería P alau, 1956. S ANHUEsA, María: "Minguet e Yrol", en Diccionario de la música española e hispanoamericana . (E. Casares, dir .) Madrid, Sociedad General de Autores y Editores, 2001.

18 Estructura del ejemplar E-Mn R/4203, con base en el cual se realiza este estudio.

19 Minguet e Yrol, P.: El noble arte de danzar a la francesa, op. cit., p. 19.

20 Ruiz Mayordomo, M José: "Espectáculos de danza y baile", "De la Edad Media al siglo xviII", en Historia de los espectáculos en España. Andrés Amorós, José María Díez Borque (coords). Madrid, Castalia, 1999, p. 294. 


\section{LA BELLE DANSE, LA COUNTRY-DANSE Y LA CONTREDANSE: LA CONTRADANZA QUE LLEGA A ESPAÑA}

Rameau decide conscientemente no tratar el tema de la contradanza en ninguna de sus publicaciones ya que, a pesar de que en 1725 ya estaba bien introducida en la sociedad francesa, la considera indigna de la tradición de la danza francesa:

“[...] de plusieurs contredanses que l'on a introduites en France depuis quelque temps, \& qui ne sont pas du goût de tous ceux qui aiment la belle danse"21.

No es de extrañar que Rameau, totalmente inmerso en la danza de Luisiv, fuera reacio a introducir esos nuevos bailes dieciochescos en su obra. Para él, la perfección en la ejecución de los pasos es la base de la danza, mientras que en la contradanza, la construcción de las figuras de grupo cobra importancia en detrimento de la corrección de los pasos. En esa línea, De la Cuisse, tratadista y autor de v arias compilaciones de contradanzas, escribe en 1762: "paraissent plutôt se promener que danser et cro yent en faire assez que de suivre le chemin de la figure" 22 . La queja de De la Cuisse se refiere a los bailarines que se limitan a ejecutar las figuras sin mostrar interés por la perfección de los pasos.

Minguet e Yrol también hace referencia al tema de la perfección en los pasos, pero, aunque es consciente de los pasos que hay que desarrollar, es mucho menos riguroso con su corrección:

"Nótese, los que no sepan hacer passos de minué, de rigodón, boréas, assamblés, chassés, contratiempos, balancés... hagan una similitud, que en las contradanzas pocos los observan".

En cualquier caso, aunque tanto Ferriol como Minguet se basan en la obra de Rameau, los años que separan la publicación de las obras francesas de las españolas, hacen que en tiempos de Ferriol y de Minguet, la contradanza sea ya obligada en un tratado sobre danza francesa. Además hay que tener en cuenta que España no ha vi vido ese fragor de la danza de Luis XIV y que por lo tanto no v e en la contradanza una contaminación de la auténtica belle danse.

En los primeros años del siglo XVIII llegan a España los dos tipos de contradanza que existían en París: la contradanza inglesa, también llamada longway o larga y la contradanza francesa, contredanse o cuadrada. La primera de ellas se bailaba haciendo dos filas enfrentadas de un número $\mathrm{v}$ ariable de personas, los hombres a un lado y las mujeres al otro. La otra implicaba a cuatro parejas que formaban un cuadrado en la sala y que desarrollaban un determinado número de figuras.

Jean-Michel Guilcher analiza ambos tipos de contradanza a partir de fuentes francesas. Realiza un estudio pormenorizado de su e volución a partir de su introducción en $\mathrm{P}$ aris; la asimilación de las country-danses al entrar en contacto con el repertorio francés y la paralela gestación de lacontredanse

21 Rameau, Pierre: Le maître à danser. Paris, chez Jean Villette, 1725, p. 107.

22 La CuIsse, Sr. de: Le répertoire des bals, ou théorie pratique des contredanses, décrites d'une manière aisée avec des figures démonstratives pour les pouvoir danser facilement, auxquelles on a ajouté les airs notés . Paris, Cailleau, Castagnery, à partir de 1762. Citado en Gullcher, Jean-Michel: La contredanse, un tournant dans l'histoire française de la danse Paris, Éditions Complexes et Centre National de la Danse, 2003, p. 115. 
como danza típicamente francesa que toma elementos de su homónima inglesa al mismo tiempo que integra cierta herencia del antiguo branle ${ }^{23}$. Entre 1700 y 1723, los recopilatorios de danza publicados en Francia presentan únicamente 3 contredanzas francesas, mientras que para 1712 Feuillet y Dezais ya han coreografiado 65 contradanzas al estilo inglés. Sin embar go, esta tendencia se in vertirá en los años siguientes ${ }^{24}$ y la contradanza francesa se convertirá en la danza por excelencia de la alta sociedad; en ella se unificarán aspectos de la danza grave, como la tendencia hacia la perfección en los pasos, y elementos de las nuevas danzas, como la importancia de las figuras.

André Lorin, considerado el primer teórico francés que viajó a Londres con el fin de aprender el repertorio de country-danse para difundirlo más tarde en la corte de Luixıv, confiesa que antes de enseñar las danzas inglesas en Versalles, se encar gó de "habiller les contredanses à la française", dándoles un toque más parecido a la danza noble francesa, adaptando los pasos y el estilo de ejecución. De esta forma, en Versalles bailaron unas country-danses afrancesadas, además de crear sus propias contredanses.

En el estudio de las contradanzas españolas hay que tener esto en cuenta ya que las contradanzas inglesas que se publican en España han lle gado a tra vés de Francia, y ya han pasado por ese primer filtro de afrancesamiento. Así, las contradanzas que llegan a España son las inglesas "afrancesadas" y las francesas.

\section{La contradanza en el tratado de Ferriol y Boxeraus}

"Los bailes de más diversión y más apreciación en el gusto de la jurentud son las contradanzas, pues la mayor parte de las funciones se reducen a bailes de esta calidad" 25 .

A pesar de ese éxito que él mismo anuncia, Ferriol es previsor al tratar el tema de la contradanza. Consciente del poder de los moralistas en la España moderna y mostrándose de acuerdo con sus principios, comienza su explicación con un aviso dirigido a los compositores sobre la necesidad de la corrección en las contradanzas:

"los compositores deben tener especial cuidado, poniendo cuanto esté de su parte en disponer los bailes de modo que se aparte el menor ademán indecente y que al paso, que la di versidad de sus mudanzas sean de agradable di versión, muevan los ánimos a una honesta recreación; pues no sin fundada razón se lamentan los predicadores, corrigiendo lo pernicioso de algunos bailes, que por la pro vocación de sus movimientos debían prohibirse; y en este supuesto he procurado con el mayor desv elo escoger y componer los bailes de más decencia”26.

23 GuILCHER, Jean-Michel: op. cit, p.72.

24 Ibid., pp. 64 у 65.

25 Ferriol y Boxeraus, Bartolomé: op. cit., Tratado III, Capítulo iv (el título de Capítulo iv aparece tachado en este ejemplar M/860), De las etiquetas y explicaciones de las contradanzas, p. 42.

26 Ibid., pp. 34 y 35. 
Pasa a continuación a presentar algunas de las leyes de cortesía que rigen en los bailes y a aclarar cómo se debe comportar el bailarín de contradanza cuando está en el e xtranjero. Como anexo de este último punto, adjunta un bre ve diccionario terminológico (pronunciación y traducción al castellano) con palabras técnicas de danza en italiano, inglés, francés y catalán.

Ferriol anuncia cuatro modos diferentes de bailar contradanzas:

"Las cuadradas o en cuatro son de cuatro pares, uno en el testero de la sala, otro enfrente y uno en cada lado y se acaba después de haber hecho las cincuenta diferencias anteriormente e xplicadas (...). De dos pares, es uno en el testero y otro enfrente; y casi todas las que se bailan de cuatro pares, se pueden bailar de dos. Las largas o a lo largo, es todos los hombres a un lado y las damas a otro, que en esta forma las usan ordinariamente los Escoceses, Ingleses... y se acaban al volver a su sitio, con tal que hayan llegado hasta lo último de la sala [...]. Las Redondas o en redondo, se plantan de la misma forma que las lar gas; y sólo se diferencia en que lo que baila el primer hombre con su Compañera, lo ejecuta con la $2^{\mathrm{a}}$, la $3^{\mathrm{a}}$, la $4^{\mathrm{a}}$..., formando un círculo y la primera señora hace lo mismo con los hombres".

Comienza la descripción de las contradanzas lar gas o inglesas, a las que dedica seis páginas; en primer lugar explica el significado de algunos signos de repetición musical y se detiene después en la descripción de las figuras (ver cuadro 1). Sigue el mismo método para la contradanza cuadrada; sin ningún tipo de introducción, se lanza a la enumeración y descripción de las figuras, que en este caso se denominan diferencias (ver cuadro 1) y que son presentadas de manera bastante gráfica. Por ejemplo,

"La Cruz de Malta, es darse las cuatro damas las manos derechas y con la izquierda tener asida las derecha del compañero y dar una vuelta entera caminando hacia delante. También se hará dando los cuatro caballeros las manos izquierdas y con las derechas tener asidas las damas. Y también estando dos hombres y dos señoras adentro".

Una vez descritas y explicadas las figuras, Ferriol enumera ordenadamente las cincuenta diferencias de la primera parte de las contradanzas de cuatro pares, de modo que nos transmite e xactamente el modo de realizar las figuras en su correcto orden ${ }^{27}$. Para concluir la contradanza, las parejas deben caminar hacia el centro de la sala hasta encontrarse y hacer las re verencias del minué, que han sido explicadas al comienzo de este tratado III.

Sin haber entrado a analizar ejemplos concretos, ya en estas explicaciones teóricas se echa en falta un elemento que no habría f altado en los tratados franceses: la descripción de los pasos. Ferriol no se preocupa de los pasos ni en las contradanzas inglesas, ni en las francesas. En las inglesas, ese proceder podría parecer normal ya que ni siquiera los propios tratados ingleses decountry-danses se preocupaban por ilustrar ese tema ${ }^{28}$. Sin embargo, en las contradanzas francesas la definición de los pasos e xiste e importa. Incluso yendo más allá y analizando las contradanzas inglesas introducidas en Francia, vemos que los franceses habían fijado sus pasos en aquel proceso de afrancesamiento de la country-danse.

27 Ferriol y Boxeraus, Bartolomé: op. cit., Tratado III, Capítulo IV, Diferencias de la primera parte de las contradanzas de cuatro pares, pp. 259-262.

28 GuILCHER, Jean-Michel:, op. cit., p. 56. 
De hecho, Feuillet, en su primer Recueil de contredanses, publicado en 1706 y en el que se presentan contradanzas al estilo inglés, ya define los tipos de pasos que deben utilizarse:

"les pas les plus ordinaires aux contredanses, e xcepté celles qui sont sur des airs de menuet, sont pas de gavotte, chassés de côté, pas de bourrée, et de certains petits sauts en a vant tant d'un pied que de l'autre..."'29.

Teniendo en cuenta que la contradanza en España se introduce a tra vés de Francia y no de Inglaterra, lo lógico habría sido que Ferriol hubiera hecho alguna alusión al modo de ejecutar los pasos dentro de las figuras. En este sentido, los autores españoles toman sus propias decisiones. Está claro que para ellos la contradanza es un género totalmente nuevo que no tiene nada que ver con la tradición de danza española que se había practicado durante los reinados de los Austrias ${ }^{30}$. Para ellos el interés de la contradanza radica en la relación con el grupo, en la realización de las figuras y eso es lo que se desprende de sus tratados.

De todas formas, aunque en estas primeras e xposiciones teóricas Ferriol no dé ningún detalle sobre los pasos, más adelante, en los ejemplos de contradanzas concretas, sí hace alguna alusión a ciertos tipos de pasos, aunque no de manera sistemática, como era práctica entre los franceses. Por ejemplo la descripción de la Contradanza larga del Passapié de Dragon dice así:

“Todos los hombres acercarse a las damas con un Passo de Minuete, Balancé, Passo atrás, y una vuelta, cada uno en su sitio..."

Este es el modo en que se an a mencionar los pasos en este tratado, sin profundiząisin especificar con qué pie se comienza el paso de minué, hacia qué lado se realiza el balancé o de qué manera se desarrolla la vuelta.

Ferriol presenta 21 ejemplos prácticos de contradanzas (v er cuadro 2), entre los que sólo encontramos 2 coreografías y 15 partituras musicales. Cada contradanza puede bailarse en cualquiera de los cuatro estilos ya descritos (lar gas, en redondo, cuadradas o de dos parejas); la música será la misma para los cuatro, pero las coreografías sólo hacen referencia a uno de ellos. Únicamente las explicaciones marcarán las diferencias entre los estilos.

29 Feullnet, Raoul-Auger: Recueil de contredanses mises en chorégraphie..., op. cit., Paris, l'auteur, 1706, Préface.

30 Ver Esquivel Navarro, Juan: Discursos sobre el arte del dançado, Sevilla, Juan Gómez de Blas, 1642. S uBIRA, José: "Libro de danzar de Don Baltasar de Rojas P antoja compuesto por el maestro Juan Antonio Jaque, s. XVII", en Anuario Musical, v, (1950), pp. 190-198. Antón PRiasco, Susana: "Reglas del danzar: edición de un manuscrito español de danza del siglo xvi”, en Revista de Musicología, no 1 (1998), pp. 239-245. BECKER, Danielle: "Música de instrumentos, bailes y danzas en el teatro español del siglo de oro", en Cuadernos de teatro Clásico español, 3, (1989), pp. 171-190. Esses, Maurice: op. cit. RuIz MAYORDOMO, Ma José: "Espectáculos de danza y baile", "De la Edad Media al siglo xvIII"..., op. cit. 


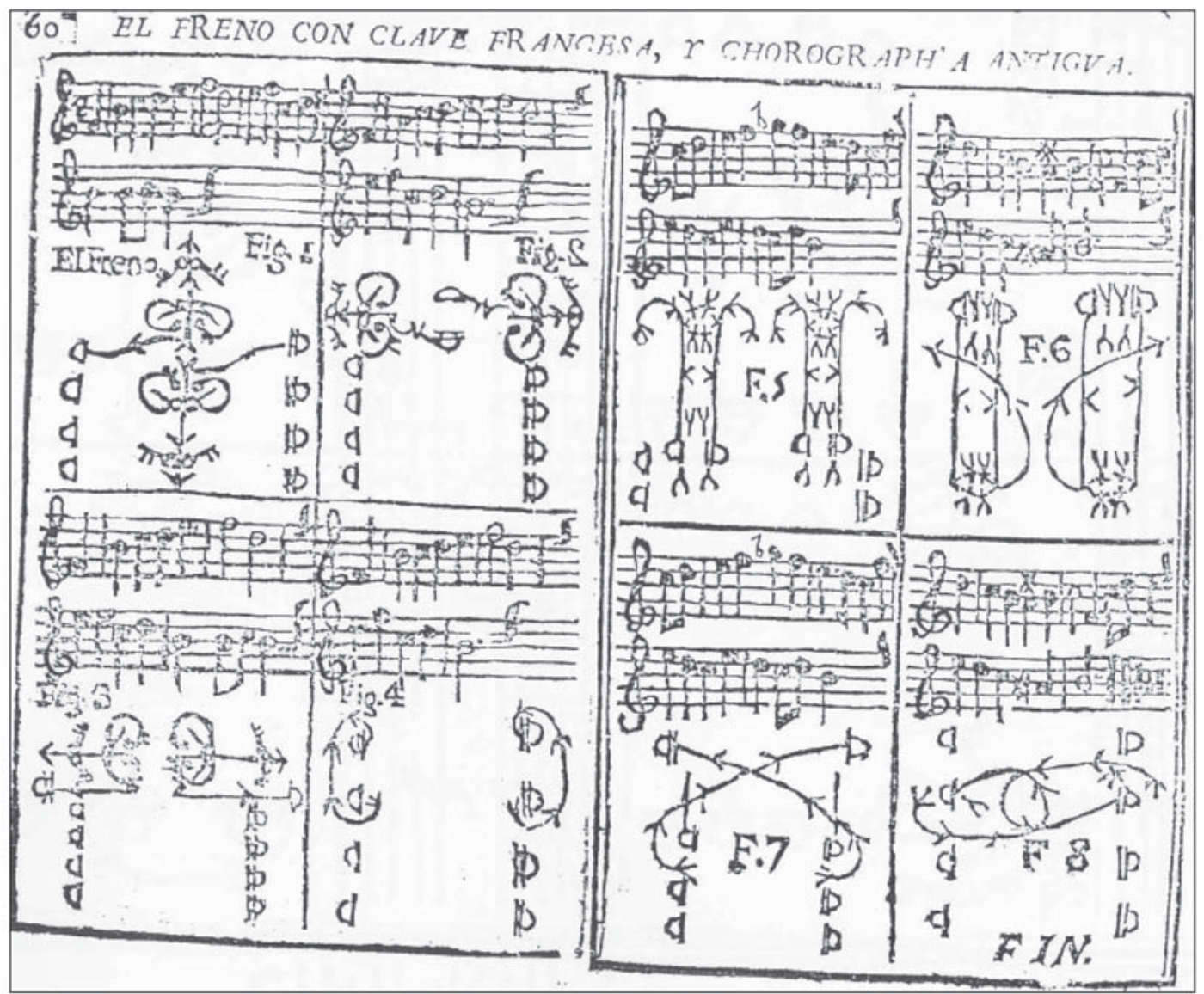

Ilustración 1. El Freno. Contradanza inglesa. Bartolomé Ferriol: Reglas útiles para los aficionados a danzar (Capua, Joseph Testore, 1745), tratado III, “De cómo se han de bailar las contradanzas”, p. 60.

La técnica que utiliza para plasmar el movimiento es muy poco precisa. Solamente introduce dos contradanzas con coreografías que son originarias de tratados franceses: la primera de ellas, El Freno, utiliza la notación antigua para una contradanza inglesa, es decir como él mismo había explicado, la del tratado de Feuillet; la se gunda, La Gentil, contradanza francesa, está transcrita en notación moderna, la de Pierre Rameau. El hecho de que sólo utilice notación coreográfica para dos ejemplos entre los veintiuno que incluye en su tratado, deja ver que Ferriol no manejaba con soltura este tipo de sistema.

En los casos en los que se presenta la música nos encontramos con el problema de la correspondencia entre música y movimiento, como ocurre también con la notación francesa. Si incluso en los dos ejemplos de coreografías (en los que cada figura se representa junto con su melodía) es difícil cuadrar con precisión la música y el movimiento, en el caso de las explicaciones en prosa no es posible establecer ningún tipo de correspondencia entre la partitura y la descripción de las figuras. 
Incluso se pueden observ ar algunas contradicciones. Por ejemplo, en la introducción a la contradanza establece que "mientras se baila, ninguno de los circunstantes batirá el compás, ni hará figuras con la cabeza, manos, ni pies", sin embar go, en la descripción de la contradanza El tambor austríaco rectifica: "en estas tres contradanzas siguientes se lleva el tono con los pies".

Al final de su obra habla de un søundo tomo en el que promete adjuntar "muchas Contradanzas nuevas y otros bayles que estén más en moda", pero a día de ho y no se tiene noticia de su e xistencia.

\section{La contradanza en el tratado de Minguet e Yrol}

De los cinco tratados que componen la obra de Minguet, el primero en hacer referencia a la contradanza es el titulado Cuadernillo curioso de veinte contradanzas nuevas, escritas de todas quantas maneras se han inventado hasta ahora ${ }^{1}$, que no lleva fecha y que reproduce casi íntegramente las explicaciones teóricas sobre la contradanza que habíamos visto en el tratado de Ferriol (ver cuadro 1). Se puede fechar en los años 60 del siglo xVIII: en su introducción hace referencia a los bailes de máscaras, que se ponen de moda en esa década ${ }^{32} \mathrm{y}$, además, introduce las se guidillas, bailes que se implantan entre las clases pudientes en una época posterior a la de Ferriol.

Antes de presentar las v einte contradanzas que promete en el título, Minguet comienza introduciendo las mismas explicaciones teóricas que Ferriol: primero las figuras que componen las contradanzas largas y después las de las contradanzas cuadradas que, se gún él, sirven también para bailar las seguidillas, que se pueden bailar con música cantada o instrumental, "poniéndose los hombres a un lado y las mujeres en otro mudándose como se hace en las contradanzas lar gas y redondas". Además hace referencia a la práctica del baile de las se guidillas en el e xtranjero; se gún Minguet, los extranjeros las cantan y las bailan en su lengua, denominándolas Contradanzas españolas. Se trata de la única referencia a unas contradanzas que no sean inglesas o francesas de todas las fuentes analizadas.

En la parte de las contradanzas cuadradas, Minguet añade una figura que no había sido descrita por Ferriol: el Caracol ("es darse la mano y la dama da vuelta passando la cabeza por debaxo del brazo del caballero; también pueden passar los dos") 33. Acto seguido comienza Minguet la "Explicación de las xx contradanzas dedicadas a las cinco letras vocales, para que el aficionado las ponga los nombres que gustase". Se trata de cuatro contradanzas por cada vocal, es decir:

31 Minguet e Yrol, Pablo: Cuadernillo curioso de veinte contradanzas nuevas. Madrid, en la imprenta del autor vive frente la cárcel de corte, encima de la Botica, donde se hallará éste y todas sus obras útiles, y en los Libreros, Gradas de San Felipe, sf.

32 Esses, Maurice: op. cit., p. 457. K ANy, Charles E.: Life and manners in Madrid (1750-1800) . Berk eley, California, University of California Press, 1932, p. 327.

33 Minguet e Yrol, Pablo: Cuadernillo curioso..., op. cit., p. 6. 
Contradanza de la letra A: larga, de dos pares, en quadro, redonda.

Contradanza de la letra E: larga, de dos pares, en quadro, en redondo.

Contradanza de la letra I: larga, de dos pares, de quatro pares, en redondo.

Contradanza de la letra $O$ : larga, de dos pares, quadrada, redonda.

Contradanza de la letra $U$ : larga, en redondo, en quadro, de dos pares.

Las descripciones de las contradanzas siguen el mismo estilo que las de Ferriołplicaciones someras que pueden conducir más o menos al bailarín pero no reproducen actamente todos los movimientos que conlleva la danza. A veces da los nombres de los pasos, como en el ejemplo siguiente los chassées y el rigodon, pero no es riguroso con ese tema. La Contradanza de la letra E en quadro dice así:

"Los pares principales harán lo mismo que de dos pares; y al mismo tiempo los de los lados marcharán del lado izquierdo los caballeros, y las señoras del derecho con tres Chassés y Rigodon. Caminar adelante, y pasamanos, caminar de lado asidos de las manos (como han empezado los primeros) $\mathrm{P}$ asamanos, palmada, y vuelta con su compañera"34.

A diferencia de Ferriol, Minguet dedica una página de su tratado a la e xplicación de los pasos que más se estilan en las contradanzas. Cita el paso de minué, el contratiempo y el balancé y remite al lector a las descripciones del passapié para su consulta. Se detiene a e xplicar el paso de rigodón, que se compone de un contratiempo saltado y una cabriola o assamblé $e^{35}$; el paso de burea, que contiene un medio cupé ${ }^{36}$, un paso andando sobre la punta y un medio salto; y el floreo, que se realiza con un demicupé y dos pasos andando (pas marchés).

Debido a varias dudas y pre guntas entre los lectores de su primer tratado sobre la contradanza, Minguet publica una Breve explicación de diferentes danzas y contradanzas, demostradas con media chorographia. Se trata de nueve páginas en las que repite parte de la información que ya ha dado en la obra anterior añadiendo alguna parte en la que aumenta la información.

Y sigue copiando literalmente a Ferriol en De cómo se han de baylar las contradanzas, donde repite las descripciones de los cuatro estilos de contradanza. Incluso mantiene un comentario que Ferriol había escrito entre paréntesis referente a la honestidad de los bailes (circunstancia que busco con el mayor cuidado). Como novedad, aporta consejos a los aficionados a la danza:

“el aficionado que no haya visto la contradanza que se quiere baylar sea a lo largo, redonda..., póngase a los últimos y mire a los principales cómo la empiezan...”.

En este sentido se dirige también a los maestros solicitándoles que no innoven en sus clases sino que mantengan el orden de las figuras establecidas para cada danza para evitar problemas en los bailes o saraos en los que a veces

34 Ibid, p. 10.

35 Dos pasos diferentes que Minguet asimila en uno solo.

36 Traducción que no siempre utiliza del demi-coupé. 
"he visto baylar contradanzas y hacer algunas mudanzas o vueltas tan violentas que ha sucedido el soltárseles las manos, y dar unos golpes por las mesas otros por las sillas y otros salir escalabrados, causando grande risa o pesar a todos los asistentes" ${ }^{\prime 37}$.

Termina este breve "tratado" con una página dedicada a la explicación de los movimientos de los brazos en la que recoge los temas principales: los tres ejes de moimiento (muñecas, codos y hombro), la correspondencia con las piernas y la oposición entre brazos y piernas. En cualquier caso, este corto apartado no puede transmitir al aficionado la variedad de movimientos de brazos que recoge la práctica de la danza francesa; es un mero recordatorio de escaso valor práctico.

Por fin llegamos a las partes prácticas de su obra: enEl noble arte de danzar a la francesa y española se presentan, entre otras danzas, 16 contradanzas con música, explicaciones en prosa y coreografías. Esta vez Minguet se aleja de las influencias de Ferriol y se guía por las últimas publicaciones francesas. Ya no se habla en cada contradanza de cuatro estilos de baile para la misma música, sino que las francesas v an a tener sus explicaciones, sus figuras y su música y las inglesas las suyas. Para las contradanzas francesas introduce el sistema de notación coreográfica de De la Cuisse ${ }^{38}$ (Paris, 1762) en el que, por primera vez, se ponían en relación música, descripciones en prosa y dibujos de figuras ${ }^{39}$.

En el prefacio de su obra, De la Cuisse presenta así su nuevo modo de coreografiar:

“j'ai substitué aux termes et aux figures corégraphiques de la danse, qui ne sont guères connus que des maîtres de l'art, une nouv elle Chorégraphie et des explications plus longues à la vérité, mais aussi plus simples et plus à la portée de tout le monde" 40 .

Minguet sigue esa misma línea:

"lector, éste es el perfecto modo de escribir y delinear los bailes, y no los que he visto, que si no hay quien los enseñe no se entienden; y en este arte no sirve la explicación sin la demostración" ${ }^{41}$.

En este nuevo método, se representan las figuras con dibujos diferentes y cada bailarín se identifica con uno, al que debe seguir durante toda la danza. Como De la Cuisse, Minguet representa figuras con el cuerpo redondo, triangular, cuadrado o en línea, blancos o ne gros, para representar las parejas; es decir, en cada pareja, sea redonda, triangular o cuadrada, la mujer será la blanca y el hombre el negro; en el caso de la figura en línea, una de las dos se representará con unos puntos a los lados. Minguet introduce una lámina para cada contradanza y en cada lámina se observa la línea melódica, las figuras y las explicaciones. Todas las contradanzas que presenta con este nue vo sistema de notación son a la francesa, o cuadradas:

37 Minguet e Yrol, Pablo: Breve explicación de diferentes danzas y contradanzas demostradas con media chorographia, op. cit., p. 8.

38 La CuISSE, Sr. de: op. cit.

39 GUILCHER, Jean-Michel: op. cit., p. 93.

40 GuILChER, Jean-Michel: op. cit., p. 94.

41 Minguet e Yrol, Pablo: El noble arte de danzar a la francesa y a la española, op. cit., p. 5. 
La estrella, contradanza nueva.

La idea buena, contradanza nueva.

La invención bella, contradanza nueva.

La greca marrueca, contradanza nueva demostrada por coreografía moderna.

Los petimetres y petimetras, contradanza nueva demostrada al estilo moderno.

Los muchachos hermosos, contradanza nueva demostrada al estilo del autor.

Los presumidos y las presumidas, miscelánea nueva.

Los bailarines, contradanza mixta y nueva.

Las tres primeras son las más sencillas: dos melodías de cuatro (la primera) u ocho compases (las siguientes) de música en ritmo binario y tres figuras de danza que se repiten cambiando el orden de las parejas. La primera figura se realiza durante los ocho primeros compases de la música y las otras dos duran cuatro compases cada una. El resto de los movimientos son repeticiones de las mismas figuras.

Las descripciones en prosa siguen la línea de las que ya han sido presentadas pre viamente, pero en el caso de La invención bella, Minguet nos enseña un vocabulario nuevo:

“este zarzé [refiriéndose seguramente al chassée], algunos le llaman el Coco [...] Algunos mudan los nombres en las diferencias, por alemanda dicen Espada y daga; a otras la Noria, el Molino....".

Las siguientes contradanzas son más lagas. Por ejemplo, los Petimetres y las Petimetras presenta doce figuras y tres melodías de ocho compases cada una en ritmo binario que se repiten dos $\mathrm{v}$ eces. Como en los ejemplos anteriores, Minguet marca en cada figura el número de compases que ocupa: la primera figura se realiza durante los ocho primeros compases y, excepto la séptima figura que ocupa dos, las demás tienen una duración de cuatro compases cada una.

Cabe hacer una reflexión sobre el título que eligió Minguet para esta contradanza, título que evidentemente no copió de De la Cuisse. Como es bien sabido, el término petimetre ${ }^{42}$ designaba desde un punto de vista satírico a un tipo de persona que imitaba los modos de vida franceses: se v estía a la francesa, se re gía por un protocolo heredado de Francia, conse guía productos del país v ecino y, evidentemente, bailaba "a la francesa". Por eso es rele vante el hecho de que Minguet se apropie de esa sátira e incluya precisamente a esos personajes satirizados por vi vir a la francesa en el título de una contradanza cuadrada coreografiada con notación de un tratadista francés. Sin duda consciente del

42 Referencias sobre los petimetres se pueden encontrar en fuentes y bibliografía v ariadas. Ver El tocador o libro a la moda, escrito en letra de color de rosa, pulimentado y carnizado. Madrid, MDCCXCVI. Zamácola, Iza: Elementos de la ciencia contradanzaria, para que los Currutacos, Pirracas y Madamitas de Nuevo Cuño puedan aprender por principios a bailar las contradanzas por sí solos o con las sillas de su casa Madrid, en la imprenta de la viuda de Joseph García,MDCCXCVI. FERNÁNDEZ DE RoJAs, Juan: Libro de moda o ensayo de la historia de los currutacos, pirracas y madamitas de nuevo cuño, escrito por un filósofo currutaco y corregido nuevamente por un señorito pirracas . Madrid, en la imprenta de Fermín Villalpando, 1795. SuBIRÁ, José: "Petimetría y Majismo en la literatura", en Revista de literatura, Iv/8, (1953), pp. 267-287. Andioc, René: "Les Français vus par les "tonadilleros" de la fin du XviII siècle", en Bulletin Hispanique, t. 96/2, (1996), pp. 353-375. Lolo Herranz, Begoña (coord.): La tonadilla escénica: paisajes sonoros en el Madrid del s. XVIII. Madrid, Museo San Isidro, Ayuntamiento de Madrid, Consejería de Cultura, Educación, Juventud y Deportes, 2003. 
éxito que comenzaban a tener las críticas hacia lo e xtranjero, pensó que un título pro vocativo podría dar de qué hablar, lo que siempre conlleva una cierta dosis de publicidad.
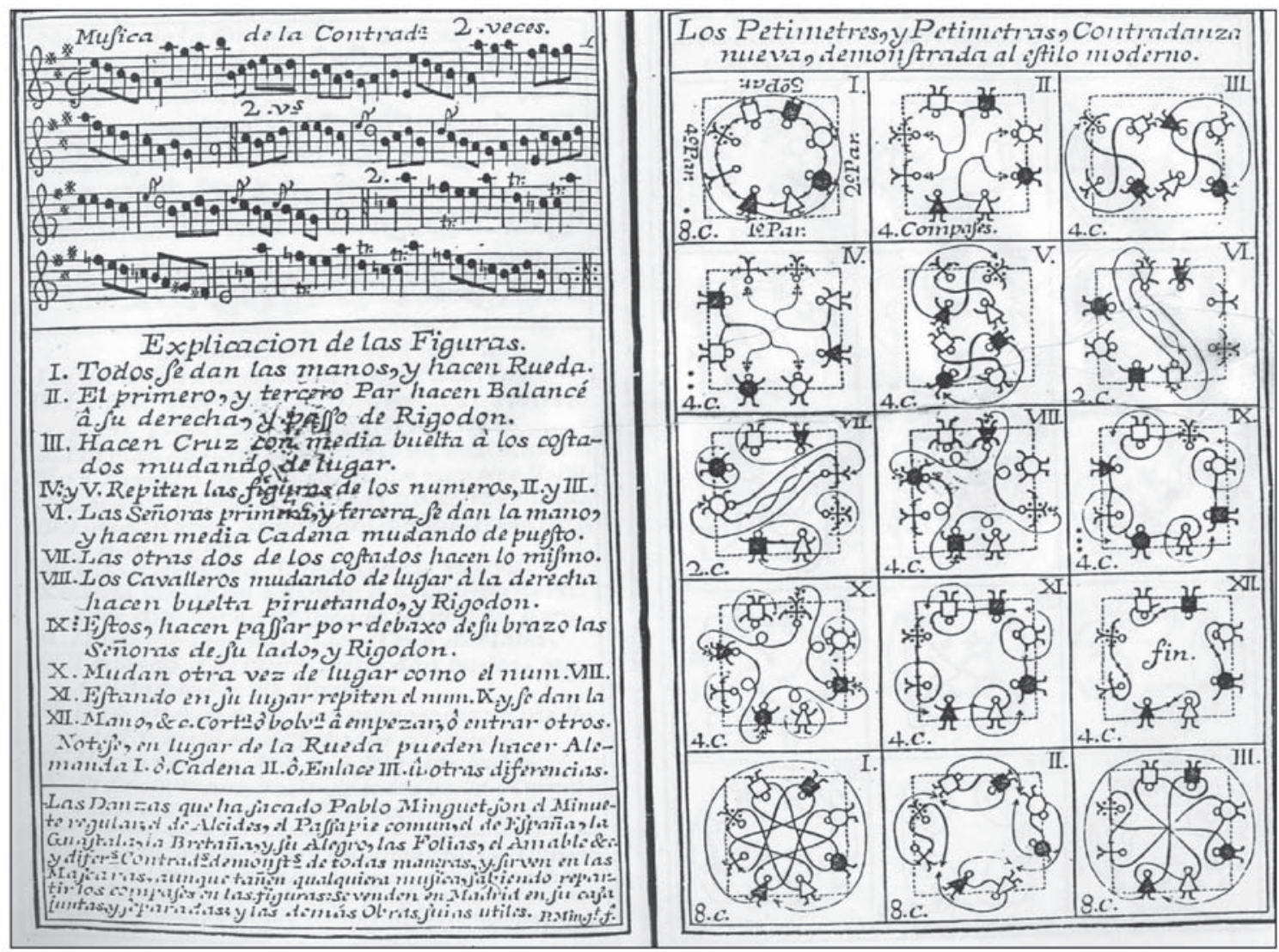

Ilustración 2. Los petimetres y las petimetras. Contradanza francesa. Pablo Minguet: El noble arte de danzar a la francesa y a la española, (Madrid, el autor, 1758), p. 13

Las demás contradanzas cuadradas presentan una estructura similar a las ya citadas: música en ritmo binario, un número v ariable de figuras y unas e xplicaciones no muy elaboradas. Sin embar go, en las dos últimas hay una ligera variante: en la parte musical encontramos referencias a seguidillas y fandangos. EnLos presumidos y presumidas(miscelánea nueva) se presenta la línea melódica de ambos bailes en ritmo ternario y en Los bailarines se citan esas dos danzas (seguidillas y fandangos) después de la música de la contradanza. Como e xplicación a estos bailes únicamente se dan las siguientes instrucciones: "entendidas las otras contradanzas éstas son muy fáciles, en las seguidillas hagan todos cadena hasta su puesto, y bailar el findango con sus compañeras". Veremos más adelante cómo el título miscelánea se utilizará también en los recopilatorios de contradanzas de los bailes públicos como un tipo de género que mezcla la contradanza, la seguidilla y el fandango. 
A continuación siguen cuatro contradanzas lar gas y redondas ( La macarena, La discreta, La pastoril, La diligenta) en cuatro láminas con música, figuras y descripciones en prosa, pero esta vez las figuras no pertenecen al sistema de De la Cuisse, sino al de Feuillet. Minguet se inspiró de los tratados franceses para la realización de sus láminas y , puesto que el sistema de De la Cuisse sólo recogía contradanzas francesas, para las inglesas tuv o que volver al sistema de Feuillet con el que se habían coreografiado dichas contradanzas a principios del siglo XVIII.

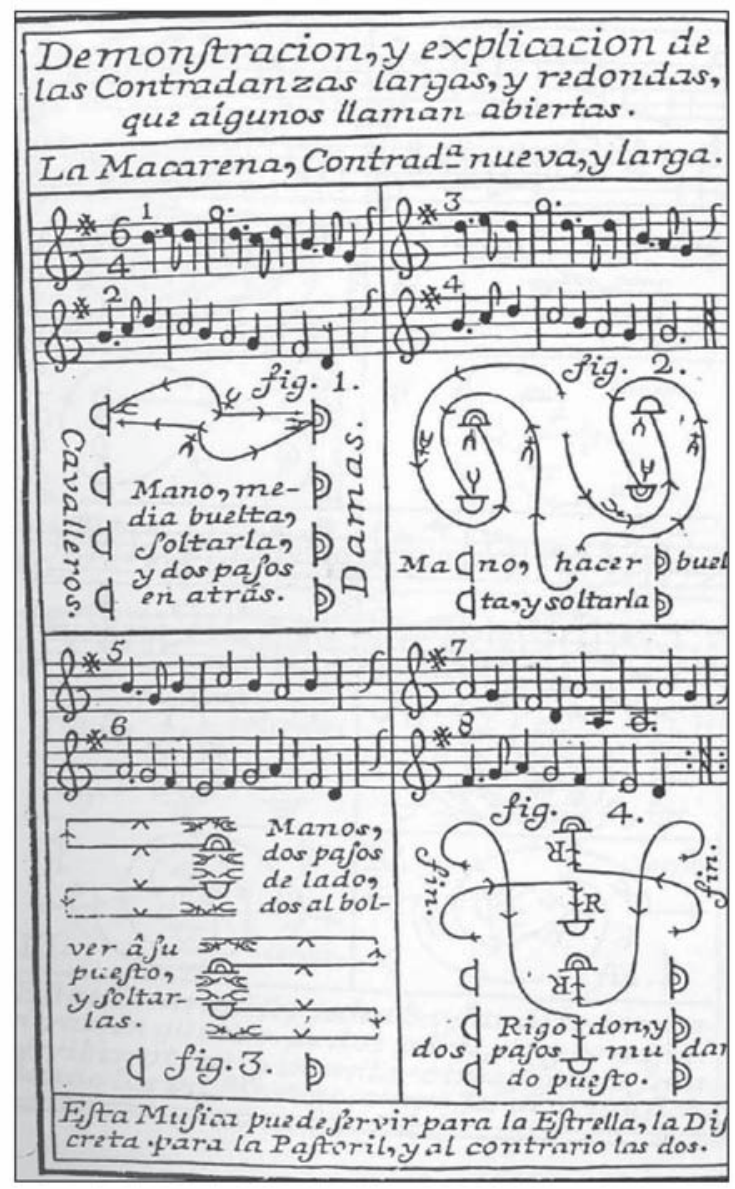

Ilustración 3. Contradanza inglesa. Pablo Minguet: El noble arte de danzar a la francesa y a la española, op. cit., p. 15.

Sólo en La pastoril Minguet vuelve a hablar de la v ersatilidad de la música de la contradanza haciendo alusión a los cuatro estilos:

"estas contradanzas se pueden bailar de todas maneras, en quadro, de dos pares... y con éstas escribir otras, e inventar otras figuras señalando los pasos... y compases de la música”. 
Aún vamos a encontrar cuatro contradanzas más llamadas airosas y cuyos títulos ya se habían visto en Ferriol, para las que no se detiene a transcribir coreografías, sino que se limita a presentar una música sencilla y repetitiva, en la línea de todas estas composiciones (6/8, dos melodías de ocho compases) con sus e xplicaciones: La Airosa Malagueña, La Catalana, El Suple Seguidillas y La Alemana $^{43}$.

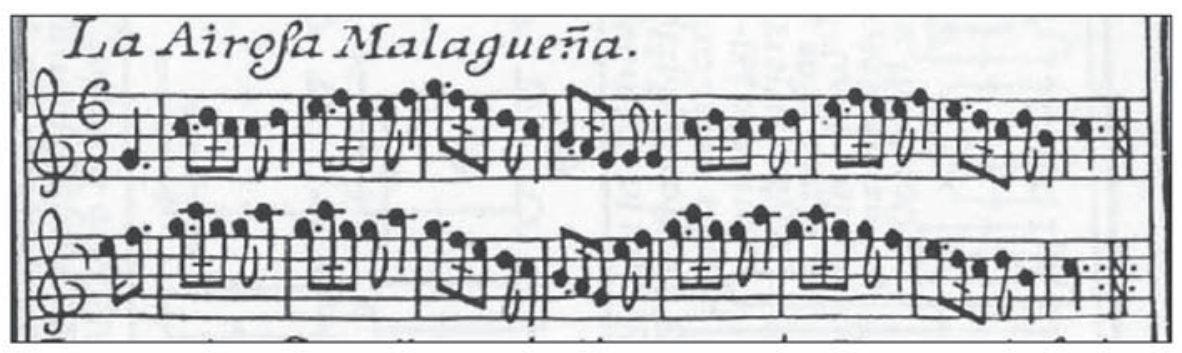

Ilustración 4. Pablo Minguet: El arte de danzar a la francesa y a la española, op. cit., p. 26.

La última contradanza de Minguet la encontramos al final de este último tratado. Se titula $L a$ Cortesana y es una contradanza cuadrada, en ritmo binario, para la que el autor utiliza la notación de Feuillet y muy pocas explicaciones. Añade también la línea melódica de un minué, en ritmo ternario, que debe interpretarse para la realización de algunas diferencias. Es la única contradanza francesa que no presenta el sistema de De la Cuisse.

No parece que Minguet hubiera asimilado los sistemas franceses de notación; todo parece indicar que se limitó a copiar contradanzas ya existentes, con el sistema de De la Cuisse para las francesas y el de Feuillet para las inglesas. Para poder corroborar dicha hipótesis, sería necesario realizar un estudio comparativo exhaustivo entre los recopilatorios de contradanzas publicados en Francia y estos raros ejemplos de Minguet, en busca de concordancias.

\section{LOS BAILES PÚBLICOS}

La moda por lo francés lle gó también a España en forma de baile público. Una práctica que se había puesto de moda en P arís en tiempos de la re gencia de Felipe II de Orleans (1715-1723) ${ }^{44}$, llega a España varios años más tarde de la mano del Conde de Aranda dentro de un programa de reformas sociales y económicas promovido por Carlos III $^{45}$.

43 Minguet e Yrol, Pablo: El noble arte de danzar a la francesa y a la española, op. cit., p. 26.

44 Semmens, Richard: The bals publics at the Paris Opéra in the Eighteenth century. Hillsdale, Pendragon Press, 2004.

45 Carreira, Xoan M.: “Ópera y ballet en los teatros públicos de la Península Ibérica”, ella Música en España en el siglo XVIII. Madrid, Cambridge University Press, 2000, p. 35. 
A partir de 1767, el teatro de los Caños del Peral, que había permanecido cerrado durante más de veinte años, es restaurado y adaptado para acoger los bailes de máscaras por un período de seis años ${ }^{46}$. Rápidamente la práctica de este tipo de baile or ganizado se propagó por la península. En dichos bailes era obligado respetar una serie de re glas perfectamente codificadas: se establecen el precio de las entradas y los horarios, los tipos de trajes que pueden lle varse y los que no, los refrigerios o aperiti vos que podrán consumirse, las danzas que se bailarán, la publicidad que se puede dar al evento...

En el caso de los bailes de máscaras de Se villa de $1768^{47}$, el reglamento dice que el precio será de 10 reales de v ellón; que el baile acabará a las 12 de la noche, pudiendo todos los in vitados cenar una vez acabado, por lo que durante el baile únicamente se servirán refrigerios, chocolate y bizcochos, no habrá cena. Sobre los trajes se estipula que estarán bien vistos los disfraces relacionados con la Comedia dell'Arte y los trajes regionales, pero quedará prohibido el travestismo, así como los disfraces de magistrados, religiosos o de clases bajas como gitanos; además deberán estar hechos de "lienzos lisos o pintados, holandillas, indianas de Cataluña o tafetanes", no pudiendo utilizarse materiales más nobles como telas de oro y plata, encajes, gasas, bordados...

En la línea de las reformas indumentarias de aquel momento, se prohíbe usar las máscaras fuera del teatro, así como “capas pardas, sombreros redondos, mantos y mantillas". Queda prohibido introducir armas blancas o de fue go en el teatro. P ara prevenir cualquier tipo de desorden, se nombran cuatro directores a los que cualquiera puede acudir en caso de necesidad.

“El baile se compondrá de Minuetes y Contradanzas y habrá uno o más maestros de baile para que ordenen las contradanzas, arreglen las parejas y las instruyan".

El baile será anunciado al público mediante carteles que se colocarán la víspera o el mismo día del evento por la mañana.

Entre los años 60 y 70 del siglo XVIII se publican v arios recopilatorios con contradanzas que se bailan en los bailes de máscaras o de carna val y que se conserv an en la Biblioteca Nacional de Madrid $^{48}$ :

- Contradanzas que se han de bailar en el teatro de esta ciudad en los bayles de máscara del carnaval de 1768, con su música y explicación de figuras, por Raf ael Rivas y Se gismundo

46 Esses, Maurice: op. cit., p. 459. Kany, Charles, E.: op. cit., pp. 327-331. E-Mn Ms 14016-1,55.

47 Reglamento para el bayle de máscaras en la ciudad de Sevilla, en este carnaval de 1768 Sevilla, en la imprenta mayor de dicha ciudad, 1768. Aguilar Piñal, Francisco: Sevilla y el teatro en el siglo XVIII. Oviedo, Teatros y estudios del siglo XVIII. $\mathrm{n}^{\circ}$ 4, Cátedra Feijóo, Universidad de Oviedo, 1974, pp. 261-265. Normas similares pueden leerse en Política y economía del bayle de máscara en la casa interina de comedias de esta ciudad de Valencia, para el carnaval del año 1769, con licencia, en Valencia, por Benito Monfort, año 1769.

48 Se sabe de la e xistencia de otras colecciones de este tipo que no se han conserv ado pero que aparecen anunciadas en la Gaceta de Madrid y en el Diario de Madrid. Ver: Sustaeta Llombart, Ignacio: op. cit., tomo III, p. 168... AcKer, Yolanda F.: Música y danza en el Diario de Madrid, Noticias, avisos y artículos 1758-1808. Madrid, Centro de Documentación de Música y DanZa-INAEM, 2007. 
Torrents, maestros y directores de ellas en el mismo teatro, Barcelona, Thomas Piferrer, impresor del rey.

- Contradanzas nuevas que se han de baylar en el teatro de la casa interina de comedias de la ciudad de Valencia en los bayles en máscara del inmediato carnaval del año 1769 , en Valencia, por Benito Monfort, 1769.

- Contradanzas nuevas con sus músicas y explicaciones de figuras para el año 1774, por José Marset. Madrid, Joachin Ibarra, 1774.

- Doce contradanzas nuevas abiertas hechas para el príncipe nuestro señor, las que se bailaron en este presente año 1775, por Don Joaquín Ibarra, impresor de Cámara de SM.

- Varias contradanzas con su música y explicación de todas las figuras (manuscrito sin fecha, seguramente recopilado hacia los años 70 del siglo XVIII).

- Contradanzas nuevas que se han de bailar en el amphitheatro de los Caños del Peral en los bailes de máscaras del inmediato carnaval de 1770 con sus músicas y explicaciones de figuras. En Álvarez Solar Quintes, Nicolás: “Contradanzas en el teatro de los Caños del Peral de Madrid”, en Anuario Musical, xx (1965), pp. 75-104 .

Con estas recopilaciones se pretendía dar a conocer el repertorio de contradanzas que se bailaban en los bailes públicos desde un aspecto práctico. Todas, excepto la del carna val de Valencia de $1769^{49}$, presentan la misma estructura: una página de música y otra con descripciones en prosa, de modo que se pueden leer juntas. Además, en las explicaciones se añaden los compases a los que pertenece cada figura, de modo que se intenta establecer una relación entre la música y el møimiento ${ }^{50}$. Por ejemplo, la segunda parte de La Constante, contradanza abierta descrita para el carnaval de Valencia de 1769 dice así:

"El primer caballero y su compañera hacen ocho por fuera para adelantar un puesto, 8 compases. Cadena entera los quatro, 8 compases" ${ }^{51}$.

Analizando las músicas de todas estas recopilaciones se establecen rápidas cone xiones. Hay un claro predominio de ritmos binarios, en 2/4: de las 23 contradanzas del carnaal de Barcelona de 1768, 16 están en 2/4, 6 en 6/8 y 1 en 3/8; de las 12 contradanzas de 1775, 11 están en 2/4 y 1 en 6/8; de las 32 contradanzas con música del recopilatorio de Marset, 27 están compuestas en 2/4 y 5 en 6/8.

En todas ellas predominan los modos mayores: DoM, SolM, ReM, LaM, F aM, SibM y MibM. Generalmente las melodías son sencillas y no conlle van modulaciones, pero en algunos casos se observan modulaciones casi siempre a las tonalidades vecinas (de LaM a MiM o de SibM a MibM), y más rara vez a sus relativos menores (de MibM a Dom).

49 Sólo presenta explicaciones, no música.

50 Este sistema se utiliza en todos los recopilatorios citados, e xcepto en el del Carnaval de Barcelona de 1768, en el que las explicaciones no dan el detalle de los compases.

51 Contradanzas nuevas que se han de baylar..., en Valencia, por Benito Monfort, 1769, pp. 1. 
La estructura musical está en relación directa con la de la danza. Las melodías se estructuran en bloques de ocho compases que se repiten. Si la música presenta $8+8$ compases (esto es $16+16$ si contamos las repeticiones), la explicación práctica tendrá dos partes, una para cada ocho compases; si la música presenta una estructura de $8+8+8$, la danza tendrá tres partes; y a una melodía de $8+8+8+8$, le corresponderán cuatro partes. Las más ab undantes son las contradanzas de dos y tres partes, generalmente se observan más inglesas en dos partes y francesas en tres, aunque puede variar.

Únicamente en el recopilatorio del Carna val de Barcelona de 1768 encontramos tres danzas en cuatro partes. Las 12 contradanzas de 1775 presentan solamente danzas en dos partes y en el recopilatorio de José Marset de 1774 hay 16 contradanzas en dos partes y 14 en tres. En este último se puede apreciar alguna v ariación en el número de compases: por ejemplo La Allemande Suice está estructurada en dos partes de dimensiones diferentes - 8+24 compases_-, aunque en la e xplicación sólo se mencionan 16 .

Se pueden observ ar también correspondencias entre contradanzas de distintos recopilatorios. El más completo es el manuscrito titulado Varias contradanzas con su música y explicación de todas las figuras, que presenta 96 contradanzas, 71 francesas y 25 inglesas. En él se recogen todas las Contradanzas nuevas que se han de bailar en el amphiteatro de los Caños del Peral en $1770{ }^{52}$, todas las del recopilatorio de Marset, e xcepto La Graciosa y todas las del carna val de Valencia de 1769, excepto El Perifollo, La Galopada, La Cadena, La Calabresa, Los Gigantones y La Carrera Italiana. Dado que el recopilatorio del carna val de Valencia no incluía la música, con el manuscrito de Varias contradanzas... se completa su información. Además, este completo manuscrito recopila 40 contradanzas más que no habían sido incluidas en los anteriores.

El recopilatorio de José Marset de 1774 incluye a su v ez todas las Contradanzas que se han de bailar en el teatro de Los Caños del Peral en 1770.

El recopilatorio del carna val de Barcelona sólo presenta cinco concordancias con los anteriores ("la inglesa nueva / la isabelita: francesa / la constante: francesa / la sin par: francesa / la miscelánea”), el resto de sus títulos son diferentes: "La zarzuela: inglesa / La generala: francesa / La diosa palas: francesa / El carnaval del teatro: francesa / La oristela: francesa / La giga de España: inglesa / Stranbg: inglesa / El tayche: francesa / La insinuación: francesa / El cascabel: francesa / Los sátiros: francesa / La priora: francesa / La frapé: inglesa / La Ernestina: inglesa / La bermeja: francesa / La salta catarineta: francesa / El Ball pla : francesa / La gayta: francesa”.

En todos los recopilatorios analizados encontramos la contradanza Miscelánea con la misma música: una primera parte que constituye la contradanza en $2 / 4$, en re menor , y con una estructura de 8+8 compases; a continuación hay un cambio de compás a 3/4 durante ocho compases (doce en la versión manuscrita), a partir del cual en dos v ersiones se lee la palabra $\mathrm{F}$ andango ${ }^{53}$. En la v ersión

52 Álvarez Solar Quintes, Nicolás: "Contradanzas en el teatro de los Caños del Peral de Madrid”, en Anuario Musical, Xx (1965), pp.75-104.

53 Contradanzas que se han de bailar... , por Rafael Rivas y Se gimundo Torrents, maestros y directores de ellas en el mismo teatro. Barcelona, Thomas Piferrer, impresor del re y, contradanza 23. Contradanzas nuevas..., por José Marset. Madrid, 
del recopilatorio titulado Varias contradanzas con su música y explicación de todas las figuras el cambio de compás coincide con las Se guidillas, que duran 6 compases, quedando otros seis para el Fandango.

Las explicaciones dividen la danza en dos partes, que curiosamente no coinciden con el cambio de medida: la primera parte se refiere a los primeros ocho compases de la contradanza y la se gunda a los restantes ocho compases, a las seguidillas y al fandango. Esta segunda parte dice así:

"los caballeros toman de las manos a sus compañeras, quedando éstas dentro, donde hacen balancé y rigodon: todos sarsé a la derecha, y rigodon y deshacer el sarsé, 8 compases: los caballeros dentro, y las señoras fuera, y repiten el balancé y rigodon, 8 compasess: cadena de søuidillas hasta el lugar opuesto; y desde él en paso de fandango retirarse hasta su lugar, los caballeros de espalda y las señoras de cara".

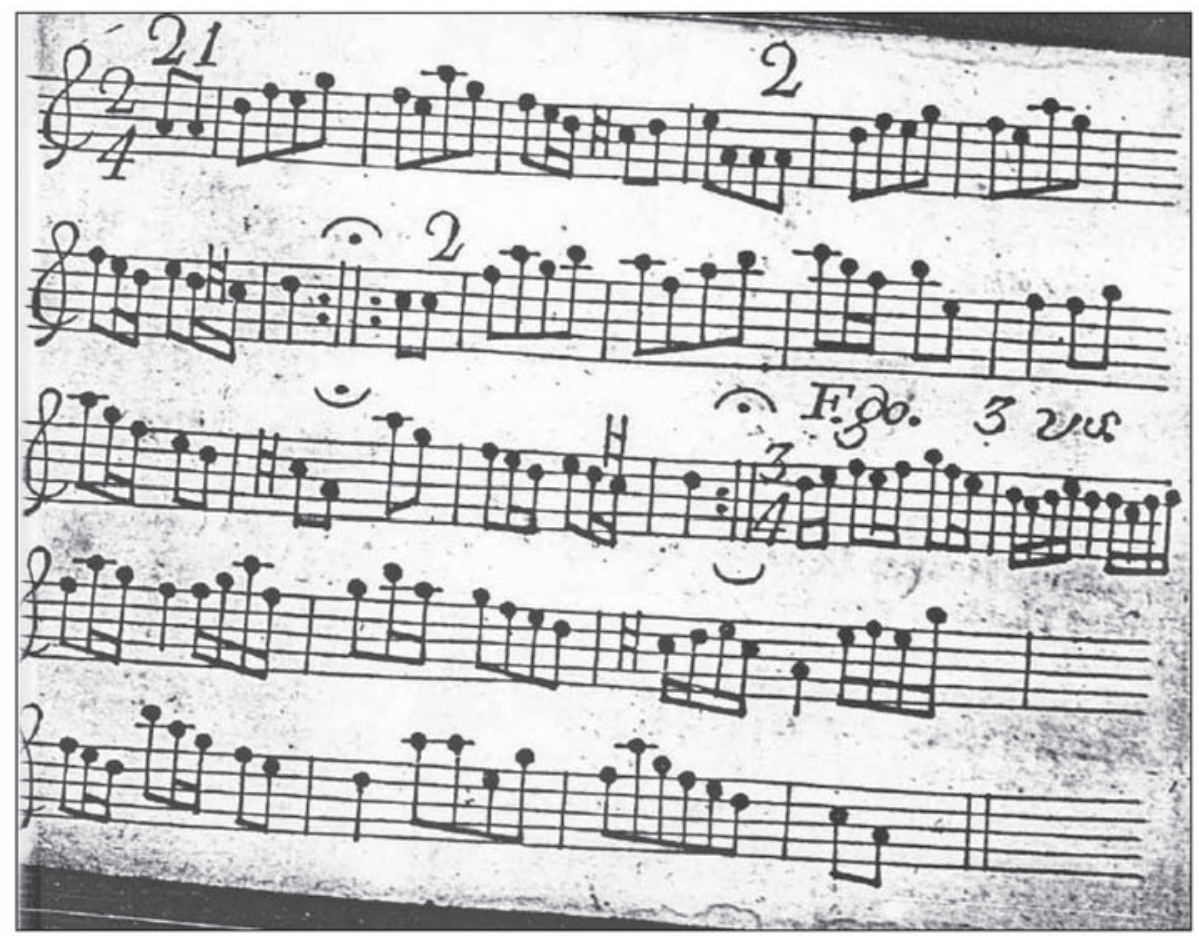

Ilustración 5. Miscelánea, contradanza 21. Contradanzas nuevas con sus músicas y explicaciones de figuras para el año de 1774, por José Marset.

Esta contradanza Miscelánea es la única que ilustra la práctica de la introducción de seguidillas y fandangos en las contradanzas, que ya había sido presentada por Minguet eYrol en uno de sus últimos tratados y cuya descripción, ya citada, se acerca bastante a ésta.

Joachin Ibarra, 1774, contradanza 21. 


\section{ConClusión}

Las fuentes analizadas muestran diferentes maneras de presentar la contradanza. Se ha señalado cómo Ferriol se centraba en las descripciones en prosa aportando cuatro estilos de danza para la misma música y sin conse guir plasmar el movimiento de manera sistemática a tra vés de coreografías (únicamente presentaba coreografías en dos ejemplos). Minguet, por su parte, demostraba estar al día de las últimas no vedades en notación francesa adoptando el sistema de notación de De la Cuisse (1762), en el que se combinaba música, explicaciones y coreografías. No obstante, hemos visto que no adopta ese estilo en todas sus contradanzas; a v eces se limitaba a dar la música con sus explicaciones y en un caso volvía a utilizar la notación francesa de la belle danse.

En las colecciones dervadas de los bailes públicos no se menciona en ningún momento la posibilidad de crear coreografías. Es muy significativo que en ninguna de estas publicaciones de carácter práctico se incluyeran notaciones coreográficas al estilo de De la Cuisse como había desarrollado Minguet e Yrol en sus últimos tratados. A pesar de toda la publicidad que dio Minguet al perfecto método para plasmar el movimiento, es evidente que para “el español”, potencial bailarín de contradanza, es mucho más fácil leer las instrucciones que aprender un sistema de códigos.

Ninguno de los sistemas de notación franceses fue asimilado por los autores españoles. Ferriol consigue transmitir la técnica de la danza francesa a nivel teórico, pero no a nivel práctico. Minguet fue el responsable de trasladar a España el nuevo sistema de notación de la contradanza y es capaz de aportar un buen número de ejemplos. Sin embaggo, si ese nuevo sistema hubiera sido asimilado por los compositores y coreógrafos, lo habríamos visto en los recopilatorios de contradanzas de los bailes públicos. Cuando los españoles comienzan a plasmar sus propias contradanzas en papel, optan por las descripciones en prosa.

Cabe preguntarse si a día de hø se pueden establecer unas características propias de la contradanza española. Del tratado de Ferriol se podría deducir que el hecho de poder bailar los cuatro estilos de contradanza con una misma música es un rasgo de la contradanza en España, pero esa práctica casi no se vuelv e a repetir. Minguet la menciona, pero después utiliza distintas e xplicaciones, músicas y figuras según el estilo de la contradanza. En cuanto a las recopilaciones para los bailes públicos, sólo se aporta un tipo de explicación para cada contradanza en música y siempre se estipula si la contradanza en cuestión es inglesa o francesa, abierta o de a ocho.

Una característica de la danza española es precisamente el haber asimilado los dos estilos (inglés o francés) de manera paralela. Musicalmente, las contradanzas publicadas en España tienen un lenguaje clásico en la línea de las prácticas de danza europeas del momento, con melodías sencillas, fáciles de recordar y una tonalidad bien establecida. En palabras de Solar Quintes, "en casi todas ellas hay reminiscencias de música clásica, diseños levemente mozartianos y haydnianos" "54. Sólo en unos pocos ejemplos se introducen danzas de cuño español como las se guidillas o el fandango, que responden a otra práctica que se instaura en la España del último tercio del siglo XVIII.

54 Álvarez Solar Quintes, Nicolás: op. cit, p. 85. 
Está claro que los compositores españoles no aprendieron a plasmar sus danzas en sistemas de notación coreográficas al estilo francés, algo que no es dextrañar teniendo en cuenta que el maestro de baile en España no contaba ni con una tradición ni con un estatus similares a los franceses. Sin embargo, las contradanzas sí que fueron asimiladas por los compositores y por el público españoles, fueron asimiladas y adaptadas a sus modos de vida, siguiendo los patrones establecidos en el clasicismo europeo prerrevolucionario.

\section{FIGURAS EXPLICADAS EN LOS TRATADOS DE FERRIOL Y DE MINGUET}

\begin{tabular}{|c|c|}
\hline CONTRADANZAS LARGAS O INGLESAS & $\begin{array}{l}\text { CONTRADANZAS CUADRADAS O } \\
\text { FRANCESAS }\end{array}$ \\
\hline $\mathrm{C}$ & Rueda de todos \\
\hline O cerrada & Paseo de minuete \\
\hline O abierta & Alemana (Alemanda en Minguet) \\
\hline Medio ocho & Dos cruces \\
\hline Ocho cerrado & Dos ruedas \\
\hline Ocho abierto & Dos cruces dobles \\
\hline Ocho entre tres ordinario & Puente \\
\hline Ocho entre tres extraordinario & Caracol (sólo en el tratado de Minguet) \\
\hline Ocho entre tres atravesado & Rueda de palmas \\
\hline Ocho entre tres doble & Rúa todos (Rueda de todos, en Minguet) \\
\hline Ocho doble & Rueda de corteza \\
\hline Cadena sencilla & Rueda de espaldas \\
\hline Cadena doble & Cruz de malta \\
\hline Cadena fría & Cambiar de compañeras \\
\hline Cadena sencilla antigua & Dos ruedas en una \\
\hline Cadena doble antigua & Dos caras \\
\hline El pasar de espaldas & Cuatro caras \\
\hline \multicolumn{2}{|l|}{ El pasamanos } \\
\hline \multicolumn{2}{|l|}{ El enlace } \\
\hline El amolador & \\
\hline
\end{tabular}




\section{CONTRADANZAS DEL TRATADO DE FERRIOL}

\begin{tabular}{|c|c|c|c|}
\hline $\begin{array}{l}\text { CONTRADANZAS EN } \\
\text { LOS CU ATRO ESTILOS : } \\
\text { larga, en redondo, cuadrada, } \\
\text { de dos pares. }\end{array}$ & $\begin{array}{l}\text { MÚSICA: la misma } \\
\text { para los cuatro estilos }\end{array}$ & $\begin{array}{l}\text { EXPLICACIONES } \\
\text { EN PROSA: una para } \\
\text { cada estilo }\end{array}$ & COREOGRAFÍA \\
\hline Passapie viejo & $3 / 4.8+8+8+8$ & 4 estilos & \\
\hline Passapie de Dragon & $3 / 4.8+8$ & 4 estilos & \\
\hline Passapie de Trompas & $3 / 4.8+8+8+8$ & 4 estilos & \\
\hline Passapie de Malé & $3 / 4.8+8$ & 4 estilos & \\
\hline El resvalón & $2 / 4.8+8$ & 4 estilos & \\
\hline El molinero empolvado & $3 / 2.8$ & 4 estilos & \\
\hline La airosa malagueña & Sin música & Cuadrada & \\
\hline La airosa catalana & $\begin{array}{l}\text { Misma música que } E l \\
\text { Resvalón }\end{array}$ & Cuadrada & \\
\hline El freno con clave francesa & $2 / 4.8+8+8+8$ & 4 estilos & $\begin{array}{l}\text { Coreografía antigua } \\
\text { para la contradanza } \\
\text { larga o inglesa }\end{array}$ \\
\hline El volante & $3 / 8.8+8$ & 4 estilos & \\
\hline El tuétano & $9 / 4.4+8$ & 4 estilos & \\
\hline Andrés Kerr & $9 / 8.4+4+4+4$ & 4 estilos & \\
\hline El tambor austriaco & $2 / 4.8+8$ & 4 estilos & \\
\hline La Charratera & $2 / 2.8+8$ & 4 estilos & \\
\hline Los mozos tontos & $6 / 2.8+8$ & 4 estilos & \\
\hline El aire & $6 / 4.8+8$ & 4 estilos & \\
\hline La hija de cupido & $6 / 4.8+8$ & 4 estilos & \\
\hline La gentil & $\begin{array}{l}3 / 4.16 \\
2 / 2.12 .8\end{array}$ & 4 estilos & $\begin{array}{l}\text { Coreografía moderna } \\
\text { para la contradanza } \\
\text { cuadrada o francesa }\end{array}$ \\
\hline $\begin{array}{l}\text { Contradanza del minuete de } \\
\text { nardo }\end{array}$ & Sin música & 4 estilos & \\
\hline $\begin{array}{l}\text { Contradanza del minuete de } \\
\text { trompas }\end{array}$ & Sin música & 4 estilos & \\
\hline $\begin{array}{l}\text { Contradanza en cuadro con } \\
\text { luces }\end{array}$ & $\begin{array}{l}\text { Con la música de La } \\
\text { Gentil. }\end{array}$ & Cuadrada & \\
\hline
\end{tabular}

Recibido: 02/10/2008

Aceptado: 10/07/2009 